\title{
Actualización: \\ Diarrea crónica en el niño
}

Chronic diarhea in children

Pascual Barán

\begin{abstract}
Resumen
La diarrea prolongada se define como el aumento de la frecuencia, la disminución de la consistencia o el incremento de volumen de las deposiciones, que no mejora y persiste por más de dos semanas. Se denomina diarrea crónica cuando su duración es mayor a 30 días, en forma continua o con intervalos de mejoría.

Las características de las deposiciones y sus síntomas acompañantes son variables según la fisiopatología de la diarrea (osmótica, secretoria, esteatorreica), su impacto en el estado nutricional del paciente y, en ocasiones, su etiología.

La diarrea crónica inespecífica de la infancia es de causa funcional. Ocurre en niños de 12 a 36 meses de edad y resuelve con el control de esfínteres. Se da en general en niños bien nutridos con antecedentes frecuentes de cólicos en los primeros meses de vida, y debe diferenciarse el síndrome de intestino irritable de la infancia.

Es poco común que los cuadros de diarrea crónica de los niños inmunocompetentes se deban a etiología infecciosa; sin embargo, las diarreas posgastroenteritis presentan alta frecuencia y se producen como consecuencia de complicaciones de las diarreas infecciosas agudas que acarrean malabsorción de nutrientes, especialmente en niños desnutridos y menores de un año. Los déficits de disacaridasas son una causa frecuente de diarrea crónica y suelen ser secundarios a injuria infecciosa (viral o bacteriana) o a alergias alimentarias; el tratamiento consiste en una dieta libre de lactosa hasta la restitución ad-integrum de las enzimas del ribete en cepillo del enterocito.

La alergia a la leche de vaca es más frecuente en niños con antecedentes familiares de este problema, puede manifestarse en forma inmediata o tardía con la ingesta del alergeno, y en general remite espontáneamente alrededor de los dos años de vida; hasta entonces se aconseja sustituir este alimento por fórmulas hidrolizadas, tratamiento que se acompaña de una mejoría rápida de los síntomas. La enfermedad celíaca suele presentarse al incorporar alimentos con contenido de gluten en la dieta del lactante, entre los 9 meses y los 2 años, pero también pueden observarse formas precoces (antes de los 6 meses) o tardías (luego de los 2 años, en la segunda infancia o incluso en la adultez). A su vez, existen cuatro formas de presentación de esta entidad, con características clínicas diferentes (sindromática o florida, asintomática o silente, latente y potencial).

La fibrosis quística es uno de los errores congénitos del metabolismo letales más frecuentes, caracterizado por una disfunción generalizada de las glándulas exócrinas que afecta con más frecuencia el aparato respiratorio y digestivo, y cuyas banderas rojas incluyen los antecedentes familiares y personales de polihidramnios, el íleo meconial, la ictericia persistente del recién nacido, la desnutrición, la deshidratación (por crisis de sudor), el prolapso rectal, las manifestaciones respiratorias recidivantes, las diarreas y el retraso del crecimiento.
\end{abstract}

\section{Abstract}

Prolongued diarrhea is defined as the increased frequency, increaded volume or decreasing consistency of passed stool, not relieved and lasting for more than two weeks. Chronic diarrhea is defined when its duration exceeds 30 days, continuously or with intervals of improvement. The stool characteristics and accompanying symptoms vary according to the pathophysiology of diarrhea (i.e. osmotic, secretory, malabsorptive), its impact on the nutritional status of the patient and, sometimes, by its etiology.

Chronic nonspecific diarrhea of childhood is often functional. It occur in children 12 to 36 months of age and usually resolves when toilet training is accomplished. It generally occurs in well-nourished children with a history of frequent abdominal colic in the first months of life. It must be differentiated from irritable bowel syndrome of childhood.

Infectious etiology is an uncommon origin for chronic diarrhea in immunocompetent children; however, post-gastroenteritis diarrhea exhibit a high frequency and occur as a result of complications of acute infectious diarrhea leading to malabsorption of nutrients, especially in malnourished children under one year of age.

Disaccharidases deficits are a common cause of chronic diarrhea and are usually secondary to infectious insult (viral or bacterial) or food allergies. Treatment of this condition consists of a lactose-free diet to restore the enzymes present at the enterocyte brush border. Allergy to cow's milk is more common in children with a family history of this problem. It can manifest itself immediately or later after the ingestion of the involved allergen, and is generally self-limited by the age of two. Until then it is advised to replace this food by hydrolyzed formulas, which elicit a rapid improvement of symptoms.

Celiac disease usually develops after exposure to gluten-containing foods in the diet of infants between 9 months and 2 years, but may also be seen in early forms (before 6 months) or late (after 2 years, late childhood or even in adulthood). There are four patterns of presentation of this entity, with different clinical features (syndromic, asymptomatic or silent, latent and potential). Cystic fibrosis is one of the most common lethal inborn errors of metabolism, characterized by widespread dysfunction of the exocrine glands that most often affects the respiratory and digestive systems, and whose red flags include: family and personal history of polyhydramnios, meconium ileus, persistent newborn jaundice, malnutrition, dehydration (sweat crisis), rectal prolapse, recurrent respiratory symptoms, diarrhea and stunting.

Baran P. Diarrea crónica en el niño. Evid Act Pract Ambul. Ene-Mar 2014;17(1):26-33.

\section{Introducción}

La diarrea crónica es un motivo de consulta muy frecuente en niños, sobre todo en los 2 primeros años de vida, y es más común en niños menores desnutridos en quienes el impacto será muy variable según su etiología.

La OMS la define a la diarrea persistente o prolongada como el incremento mantenido de la frecuencia de las deposiciones, una disminución de la consistencia fecal o un aumento de su volumen (respecto al hábito usual de cada niño) que presumiblemente inició como cuadro infeccioso agudo, no mejora y persiste por más de dos semanas. El volumen normal de las deposiciones del lactante es de 10 a $15 \mathrm{~g} / \mathrm{kg} / \mathrm{día}$ y en niños mayores de 150 a $200 \mathrm{~g} /$ día. Este cuadro se debe a la persistencia del agente infeccioso y/o a alteraciones funcionales 0 estructurales del tubo digestivo que ocurre como consecuencia de un episodio agudo. 
Cuando la duración del cuadro es mayor de 30 días se la denomina diarrea crónica; esta puede ser continua o con intervalos de mejoría, y en estos casos la etiología no suele ser infecciosa. Se deben investigar como causas a las alteraciones estructurales intestinales, las intolerancias de alimentos y las enfermedades autoinmunes o inflamatorias.

Las probabilidades de que el cuadro diarreico se prolongue en el tiempo depende de factores sociales y ambientales; tiene mayor riesgo de tornarse severa y prolongada en los pacientes con inmunodeficiencias, los menores de 6 meses, los desnutridos o con déficit vitamínico o de Zinc, los alimentados con leches de fórmula o de vaca, o los casos de mal manejo del tratamiento de rehidratación o alimentación (leches muy diluidas, ayunos, indicación de dietas hipocalóricas, hidratación con gaseosas y jugos) y de uso inadecuado de antibióticos u otros medicamentos.

\section{Presentación clínica}

La diarrea crónica persistente en el niño, ya sea por contaminación bacteriana o parasitaria del intestino y/o por alteración primaria o secundaria de la digestión o de la absorción (síndrome de malabsorción) conduce al niño en forma rápida o paulatina a un cuadro de desnutrición con distensión abdominal, retraso ponderal y aparición de signos carenciales caloricoproteicos y mineralovitamínicos. El síndrome de malabsorción (SMA) se manifiesta objetivamente con diarrea, distensión abdominal, retraso ponderal, retraso estatural, vómitos, edema, caída del pelo, lengua depapilada, piel seca, queilitis angular, anemia, retraso puberal, prolapso rectal, coagulopatías, tetania, uñas en vidrio de reloj y flatos fétidos. El paciente o su familia pueden referir irritabilidad, inapetencia, decaimiento, dolor abdominal recurrente, artralgias o cefalea. El cuadro 1 muestra el predominio de los síntomas según la edad.

Cuadro 1. Sindrome de malabsorción en el niño. Presentación según edad.

\begin{tabular}{l|c|c}
\hline Menores de cuatro años & Cuatro a diez años & Diez a quince años \\
\hline Diarrea & Riarrea intermitente & Petraso estatural \\
Distensión abdominal & Caída del pelo & Reco seco puberal, menarca tardía y falta de desarrollo genital \\
Retraso ponderal & Lengua despapilada & Tetania \\
Vómitos & Queilitis & Dolor abdominal recurrente \\
Anemia & Prolapso & Abulia \\
Irritabilidad & Tetania & Artralgias \\
Inapetencia & Irritabilidad, decaimiento & Cefalea \\
\hline
\end{tabular}

\section{Fisiopatogenia}

\section{Diarrea osmótica o malabsortiva}

Puede ser consecutiva a una alteración general de la absorción intestinal de los componentes de la dieta o puede ser una malabsorción más específica de algunas sustancias, como por ejemplo, la lactosa. Esta característica podría estar relacionada a una superficie o capacidad absortiva reducida. La infección por determinados organismos, como el rotavirus o algunas bacterias (Shigella, Salmonella o Campylobacter), que producen destrucción parcial del extremo apical de los enterocitos y disminución del nivel de disacaridasas, puede dañar la estructura vellosa del intestino delgado y llevar a una diarrea osmótica. En estos casos las deposiciones son abundantes, líquidas, explosivas, y característicamente ceden con la interrupción de la ingesta. El paciente suele presentarse con meteorismo, distensión abdominal y eritema perianal. El diagnóstico se efectúa a través de la determinación del $\mathrm{pH}$ de la materia fecal, que en estos casos es ácida, es decir, menor de $5(\mathrm{pH}$ normal: entre 6,5 y 7 ).

El cuadro 2 muestra las principales causas de diarrea osmótica.

Cuadro 2. Principales causas de diarrea osmótica

\begin{tabular}{|c|c|c|}
\hline Mala digestión & {$\left[\begin{array}{l}\text { Insuficiencia pancreática } \\
\text { Disminución de ácidos biliares }\end{array}\right.$} & $\begin{array}{l}\text { Fibrosis quistica } \\
\text { Desnutrición calórico-proteica } \\
\text { Colestasis, sobrecrecimiento bacteriano, resecc }\end{array}$ \\
\hline Déficit de disacaridasas & \multicolumn{2}{|l|}{$\left[\begin{array}{l}\text { Déficit adquirido de Lactasa o de sacarasa-isomaltasa } \\
\text { Déficit congénito de Lactasa }\end{array}\right.$} \\
\hline Defectos de absorción de los enterocitos & \multicolumn{2}{|l|}{ Abetalipoproteinemia } \\
\hline \multicolumn{3}{|l|}{ Ingesta excesiva de sorbitol } \\
\hline Infecciones entéricas & {$\left[\begin{array}{l}\text { Bacterias } \\
\text { Parásitos } \\
\text { Sobrecrecimiento bacteriano en el intestino delgado } \\
\text { Oportunistas }\end{array}\right.$} & $\begin{array}{l}\text { Campylobacter, Salmonella,Yersinia, C. difficile } \\
\text { Giardia, Cryptosporidiun, Blastocystis, etc. } \\
\text { Microbacterium avium intracelulare, Isospora } \\
\text { belli, citomegalovirus, Candida }\end{array}$ \\
\hline Inflamación de la mucosa del intestino delgado & $\begin{array}{l}\text { Alergia a la proteína de la leche de vaca y a la de soja } \\
\text { Enfermedad de Crohn o enfermedad celíaca }\end{array}$ & \\
\hline Inflamación de colon & $\begin{array}{l}\text { Colitis ulcerosa } \\
\text { Enfermedad de Crohn }\end{array}$ & \\
\hline Obstrucción linfática intestinal & Linfangiectasia intestinal & \\
\hline Trastornos de la motilidad intestinal & \multicolumn{2}{|c|}{ Sobrealimentación, diarrea crónica inespecífica, síndrome de colon irritable } \\
\hline Fármacos & \multicolumn{2}{|l|}{ Laxantes, antiácidos con magnesio, antibióticos } \\
\hline Causas endócrinas & \multicolumn{2}{|c|}{ Hipertiroidismo, Síndrome de Zollinger-Ellison, carcinoide, diabetes millitus } \\
\hline
\end{tabular}




\section{Diarrea secretoria o toxigénica}

En este caso, el intestino continúa secretando agua y electrolitos aún durante el ayuno. Se cree que este tipo de diarrea está relacionada con la presencia de sustancias intraluminales que actúan como secretagogos (P.ej. las toxinas bacteriana de la E. coli enterotoxigénica, del Vibrio cholerae o de la diarrea del viajero, los laxantes, las sales biliares, los ácidos grasos de cadena larga, etc.).

Otras causas menos frecuentes de diarrea secretoria son las infecciones entéricas (P.ej. E. coli enteroadhesiva, sobrecrecimiento bacteriano), la obstrucción intestinal, la enfermedad de Hischsprung, los tumores de la cresta neural (neuroblastoma) y la atrofia idiopática de las vellosidades.

Son las más frecuentes, principalmente detectadas en niños eutróficos. Las deposiciones son líquidas, abundantes, sin distensión abdominal, ni meteorismo. El diagnóstico se hace con coprocultivo e ionograma de la materia fecal $(\mathrm{Na}+\mathrm{fecal}$ mayor de $60 \mathrm{mEq} / \mathrm{I}^{4}$.

\section{Esteatorrea}

Es la presencia de grasa en la materia fecal. El 95\% de la grasa de las heces debería absorberse en el intestino delgado, salvo en los niños menores de 12 meses, en quienes el 10 a $15 \%$ de la grasa ingerida aparece en las heces.

La malabsorción de grasa ocurre en las patologías del intesti- no delgado (ej. giardiasis), del hígado y del páncreas. No se relaciona a problemas colónicos. La grasa en la materia fecal está asociada con diarrea osmótica y secretoria debido a que la presencia de ácidos grasos de cadena larga promueve la secreción de cloro y agua.

\section{Causas frecuentes de diarrea crónica en los niños}

Si bien existen numerosas etiologías de diarrea crónica en edades pediátricas (ver cuadro 3), nos dedicaremos a describir aquellas que, por su prevalencia, son más frecuentes en la primera infancia y lactancia y aquellas cuya detección precoz es esencial para instituir un tratamiento que permita un buen desarrollo del niño.

Se debe considerar que en muchos casos la etiología es multifactorial, y que no sería raro que en un paciente coexistan dos ó más entidades productoras de diarrea. En la mayoría de los casos el inicio del problema es de etiología viral, bacteriana o parasitaria, y luego se complica con algún grado de intolerancia a los azúcares o las proteínas de la leche y sobrecrecimiento bacteriano en el intestino delgado. De este modo se aprecia, según las cifras de algunas trabajos estadísticos, que en cerca del $67 \%$ de los casos la causa fue múltiple; en el $27 \%$, única y en el $6 \%$, indeterminadas.

Cuadro 3. Causas de diarrea crónica frecuentes según la edad de presentación.

\begin{tabular}{l|c|c}
\multicolumn{1}{c|}{ MENORES DE 6 MESES } & DE 6 A 36 MESES & MAYORES DE 3 AÑOS \\
\hline Alergia alimentaria & Diarrea crónica inespecífica & Parasitosis (giardiasis, ascaridiasis) \\
Fibrosis quística pulmonar & Exceso de bebidas y jugos & Enfermedad celíaca \\
Deficiencia congénita de disacaridasas & Parasitosis (giardiasis, ascaridiasis) & Sindrome de intestino irritable \\
Sindrome de intestino corto & Enfermedad celíaca & Diarrea por antibióticos \\
& Alergia alimentaria & \\
& Diarrea por antibióticos & \\
\hline
\end{tabular}

Diarrea crónica inespecífica de la infancia

Se define como una diarrea funcional en niños de 12 a 36 meses de edad y que resuelve en la mayoría de los casos cerca de los 40 meses de edad, en coincidencia con el control de esfínteres. Se da en general en niños bien nutridos con antecedentes frecuentes de cólicos en los primeros meses de vida, y causa de una cada tres consultas gastroenterológicas en este grupo etario.

\section{Etiología y fisiopatogenia}

La etiología de la diarrea crónica inespecífica de la infancia es aún discutida, y se atribuye a diferentes mecanismos como la dismotilidad intestinal, los desequilibrios dietarios por bajo contenido de fibras y grasas, la intolerancia a los carbohidratos, etc.

\section{Presentación clínica}

Las deposiciones son, en general, alternantes, desligadas, sin sangre, pero también pueden ser mucosas y formadas con restos de vegetales y comidas no digeridas y fibras de frutas. El número de deposiciones suele ser de uno a cuatro por día oscilando entre tres y diez, y habitualmente no se acompaña de deposiciones nocturnas. Pueden alternar en el mismo día deposiciones normales, con otras mucosas o líquidas, y este cuadro se repite tres a cuatro veces por semana. El examen físico y el crecimiento siempre son normales; no se produce deterioro del aspecto nutricional.
Algunos autores consideran que estos episodios son compatibles con el síndrome de intestino irritable de los adultos ya que estos niños suelen presentar alternancia con constipación, por lo que en el año 2006 el Comité Roma III definió los criterios para establecer este diagnóstico y diferenciarlo de la diarrea crónica inespecífica. La sensación de incomodidad o dolor abdominal debe estar acompañada de por lo menos 2 de los siguientes: 1) mejoría con la defecación, 2) alteración de la frecuencia de las deposiciones (de cuatro a más por día) 3) cambio en la apariencia de la materia fecal (deposiciones líquidas y/o con moco) 4) distensión abdominal y urgencia evacuatoria. Los síntomas se deben presentar una vez por semana por lo menos en los últimos dos meses sin alterar el estado nutricional, y habitualmente se detectan disparadores psicosociales.

La presentación del SIl casos suele efectuarse a partir los 4 años de edad, la prevalencia aumenta significativamente a partir de los 7 años y llega a un pico durante la adolescencia.

\section{Tratamiento}

El tratamiento consiste en indicar una dieta regular sin restricciones, reafirmando y tranquilizando a los padres y pacientes de que se trata de un cuadro transitorio, que no implica riesgo y que con el control de esfínteres se propiciará la retención de la materia fecal con mejoría del cuadro.

Se indica dieta sin fibra y disminución de la ingesta de carbohidratos solo en los períodos en que el niño tenga deposiciones 
líquidas, y al normalizarlas se debe restablecer la dieta habitual para la edad.

\section{Diarrea por exceso de consumo de líquido}

Se genera por el consumo excesivo de líquidos (más de 150ml $\mathrm{Kg} / \mathrm{día}$ ), y el tratamiento consiste en descender la ingesta a menos de $100 \mathrm{ml} / \mathrm{Kg} /$ día. Como consecuencia de esta medida, desciende la frecuencia y se incrementa la consistencia de las deposiciones.

Algunos pacientes presentan diarreas prolongadas cuando el contenido de grasa de la dieta es menor del $25 \%$ de las calorías totales; en estos casos se suele observar mejoría al aumentar el contenido de lípidos hasta un $50 \%$ de las calorías totales.

\section{Diarreas infecciosas}

Es poco frecuente la constatación de un origen bacteriano como causa de diarrea crónica en niños inmunocompetentes. Los gérmenes más comunes que puede causar este cuadro son el Campylobacter yeyuni, las Aeromonas, el Clostridium difficile y algunas cepas de E. coli, que suelen aislarse a través de métodos especiales de cultivo.

Entre las diarreas de causa parasitaria, las más frecuentes son producidas por Giardia y son endémicas en todo el mundo, con una prevalencia de infección crónica en países subdesarrollados de aproximadamente el $20 \%$ (es mayor en las personas con deficiencia de $\lg A$ ). Para detectar este parásito no alcanza con la solicitud de parasitológicos en fresco, y suele requerirse un aspirado del líquido duodenal, al igual que ocurre con otro parásito causante de diarrea crónica, el Strongyloides stercoralis. El Balantidium coli, el Trichuris trichura y la Entamoeba histolítica son las otras causas parasitarias más frecuentes, que en los niños con infección por HIV u otro tipo de inmunocompromiso constituyen las causas más importantes.

Las causas virales de diarrea crónica son raras, aunque se han descripto casos que sugieren que los cuadros producidos por Rotavirus, Adenovirus y Coronavirus podrían prolongarse durante varias semanas.

\section{Tratamiento}

Se debe destacar que, en caso de encontrarnos frente al aislamiento de estos parásitos patógenos, no siempre se observa una mejoría en el cuadro luego de su tratamiento, ya que la presencia en el huésped no siempre significa que constituye la verdadera etiología del cuadro (el niño puede ser un portador asintomático, como ocurre con frecuencia en la giardiasis crónica). De todas maneras, los expertos recomiendan en estos casos tratar el agente hallado y realizar controles parasitológicos o cultivos postramiento.

En el caso de diarreas de causa bacteriana, la decisión de tratamiento es difícil. La eritromicina, la espiramicina y la clindamicina no erradican completamente los microorganismos, pero disminuyen su número y suelen aliviar la diarrea.

\section{Diarrea posgastroenteritis}

Se la define como un cuadro de diarrea que persiste por más de dos semanas luego de una infección entérica aguda sin respuesta a la terapéutica habitual.

Es una de las causas diagnosticadas con más frecuencia en lactantes y niños, y se presenta en aproximadamente el 3 al $20 \%$ de las gastroenteritis agudas. En estudios realizados en varios países de América se observó que el pico de mayor incidencia se encuentra entre los 6 a 12 meses de vida, y en general, se considera que los grupos de mayor riesgo de padecer esta entidad son los niños desnutridos y los menores de 1 año. Fisiopatogenia

Esta entidad ha sido descripta en niños infectados por diversos patógenos bacterianos o parasitarios. La bacteria más asociada es la Escherichia coli enteroadhesiva, luego le siguen en frecuencia la E. coli enteropatógena y la enterotoxigénica, el Campylobacter y la Aeromona hidrofila. Entre los parásitos, el más frecuente suele ser la Giardia lamblia, seguido de Strongyloides stercoralis, Entamoeba histolítica, Criptosporidium. Isospora belli y Blastocystis hominis suelen afectar a pacientes con inmunodeficiencias. También se han reportado etiologías virales como los Rotavirus, más comunes en menores de 1 año.

La gastroenteritis aguda puede causar varias complicaciones que ayudarían a perpetuar la diarrea: atrofia de las vellosidades e injuria de la mucosa intestinal con malabsorción por déficit enzimático del ribete en cepillo, intolerancia a los carbohidratos, alteración del peristaltismo por proliferación bacteriana, sensibilización a proteínas de la leche de vaca o soja por penetración de $\operatorname{lgA}$ a través del epitelio injuriado y malabsorción de ácidos biliares.

Se han identificado varios factores de riesgo para padecer diarrea posgastroenteritis, entre los que se cuentan la utilización de alimentación artificial en los primeros meses de vida, el inicio de la diarrea aguda en el periodo neonatal o en los primeros meses de vida, la utilización de antibióticos y antidiarreicos durante los episodios agudos y las dietas hipocalóricas o ayunos prolongados en los primeros episodios de gastroenteritis aguda.

\section{Presentación clínica}

A causa de la cascada de alteraciones que se va desencadenando podemos inferir que el paciente habitualmente deteriora en forma progresiva su estado nutricional con el transcurrir del cuadro.

La presentación clínica dependería del grado de afectación intestinal y de la presencia en forma secundaria de intolerancia a disacáridos, proteínas o ambos, y la diarrea puede tener características secretorias u osmóticas.

\section{Sistemática de estudio}

El diagnóstico se orienta en una detallada historia clínica; es fundamental interrogar acerca de la procedencia del paciente, su edad, el tipo de alimentación que recibe, la disponibilidad de agua potable, las características de la vivienda y el medio ambiente en que habita, la medicación y alimentación recibida por el niño durante el episodio agudo y los eventos asociados éste (perdida de peso, deterioro del estado nutricional, etc.). Es importante determinar las características de las deposiciones, para estar atentos a la posible sospecha de patología estructural del intestino.

El diagnostico luego se sustenta con exámenes de laboratorio que cuantifiquen el grado de intolerancia a los carbohidratos y/o proteínas que presenta el paciente, aunque estas pruebas no siempre son necesarias y su solicitud dependerá del grado de alteración nutricional del niño. Si las deposiciones son líquidas, se debería solicitar parasitológico en fresco, pero si son pastosas o grumosas se debería solicitar coproparasitológico seriado con técnicas de concentración (para búsqueda de Giardias). Ante la sospecha de intolerancia a la lactosa se debería pedir determinación en materia fecal de $\mathrm{pH}$ y sustancias reductoras con y sin hidrólisis, y/o un test de hidrógeno en el aire espirado.

\section{Tratamiento}

Consiste en brindar apoyo nutricional adecuado a la intolerancia encontrada, proveer un aporte calórico y proteico equilibrado, con dieta sin fibras. En general, se indica la alimentación con leches deslactosadas o de soja y el uso de suplementos 
polivitamínicos (vitaminas A, C y D), de minerales (calcio, potasio) y/o de micronutrientes (zinc). Eventualmente, puede ser necesario emplear sales de rehidratación oral al inicio del tratamiento.

En la mayoría de los casos, se observa mejoría solo con una dieta y un aporte caloricoproteico adecuados.

\section{Intolerancia a los carbohidratos}

Los déficits de disacaridasas (principalmente de lactosa) son causa frecuente de diarrea crónica y suelen ser secundarios a injuria infecciosa (viral o bacteriana) o a alergias alimentarias.

\section{Fisiopatogenia}

El azúcar no absorbido en el yeyuno causa una diarrea osmótica con secreción intraluminal de agua y electrolitos. Al llegar al colon, los glúcidos son transformados por las bacterias en ácidos grasos volátiles (acético, butírico, etc.), ácido láctico y gas. Debido a este proceso, estas diarreas son fermentativas y se acompañan de heces característicamente ácidas.

\section{Presentación clínica}

Si bien existe una forma congénita en la que los episodios diarreicos se presentan desde el nacimiento, ésta es extremadamente rara. La más frecuente, común en lactantes y niños, es la intolerancia secundaria a la lactosa que sigue a una gastroenteritis y puede persistir por semanas o meses. En general se puede acompañar de distensión abdominal, cólicos, vómitos, falta de progreso de peso e irritación de la región perineal.

\section{Sistemática de estudio}

El diagnostico se basa en constatar la acidez de la materia fecal con tiras de medición de $\mathrm{pH}$ así como la presencia de elementos reductores en materia fecal, determinadas con tiras reactivas como el Clinitest. Otro estudio complementario útil es la prueba de hidrógeno en el aire espirado; si se encuentra un alto nivel de hidrogeniones, permite inferir que los carbohidratos no fueron absorbidos y llegaron al colon y fueron fermentados por su flora. Otra prueba muy utilizada es la de supresión de carbohidratos, basada en la mejoría clínica que sigue a la interrupción de la ingesta de estos nutrientes.

\section{Tratamiento}

Por todo lo descrito, consiste en la restricción total de lactosa por un tiempo variable hasta lograr la recuperación intestinal (en general, ad integrum, en no menos de cuatro a seis semanas), que permite observar una mejoría inmediata de la diarrea. En general, se indican las leches deslactosadas disponibles en el mercado, que se preparan en dilución al $13 \%$.

\section{Alergia a las proteínas de la leche}

La alergia a las proteínas de la leche de vaca se presenta en el 0,5 al $7,5 \%$ de la población, y su prevalencia aumenta en un $50 \%$ en la población con antecedentes familiares de este problema.

La proteína de la leche de vaca puede pasar al niño a través de la leche de madre, por lo que los niños alimentados con lactancia materna exclusiva no están totalmente protegidos.

\section{Presentación clínica}

En general, los síntomas son evidentes a la tercera ó cuarta semana de vida, con un incremento progresivo de diarrea con moco que puede o no tener sangre. En algunos pacientes se presenta exclusivamente como hemorragia digestiva baja de aparición brusca.

No es frecuente su asociación con signos de atopía. Se han visto otros síntomas acompañantes como irritabilidad, cólicos, insomnio, vómitos, otitis media aguda, rinitis, neumonitis recur- rentes, anemia e hipoproteinemia, entre otros.

Las reacciones a la ingesta de la leche pueden ser inmediatas o tardías, pero en general ocurren a las pocas horas o días. Si bien existen reportes de persistencia de este problema hasta los cinco o seis años, en la mayoría de los casos se ha observado remisión espontánea aproximadamente a los dos años.

\section{Sistemática de estudio}

El diagnóstico se sospecha por el cuadro clínico y se confirma con la restricción dietética de la proteína de la leche de vaca. Si se trata de esta entidad, se produce una mejoría rápida de los síntomas, en general a las 72 horas de la eliminación del alergeno.

\section{Tratamiento}

Se recomienda el uso de fórmulas con hidrolizados de proteínas (por ej. Progestimil o KAS1000) o bien leches de soja. Debe considerarse que las proteínas de la leche de soja son tanto o más antigénicas que la de vaca; se ha descripto que más de un $20 \%$ de pacientes alérgicos a leche de vaca tratados con leche de soja adquieren alergia a esta proteína.

Luego de no menos de 12 a 18 meses de restricción, se realiza una prueba de "desafío" con leche de vaca en forma progresiva, con aumento creciente de la cantidad ingerida, período durante el cual el paciente debe ser controlado de manera estricta.

\section{Diarrea relacionada al uso de antibióticos}

Esta entidad se presenta luego de varios días de tratamiento antibiótico, y no está causada por superinfección con Clostridium difficile. Su causa es desconocida, aunque varios autores la consideran secundaria a una modificación de la flora intestinal normal.

Las características de la diarrea son las del mecanismo malabsortivo, y se ha descripto con la utilización de polimixina, neomicina, kanamicina y bacitracina.

\section{Enfermedad celíaca}

Es un trastorno multisistémico en el cual el daño de la mucosa del intestino delgado es el resultado de una hipersensibilidad a una fracción del gluten de la dieta. Los cereales implicados son el trigo, el centeno, la avena y la cebada.

La enfermedad celíaca (EC) se manifiesta al incorporar los alimentos con contenido de gluten en la dieta del lactante, y característicamente se observan una recuperación clínica al suspenderlos y una recaída al reintroducirlos.

El período de presentación típica es entre los nueve meses y los dos años de edad, pero pueden encontrarse a veces formas precoces (antes de los seis meses) que se asemejan a una gastroenteritis prolongada o bien, formas tardías (luego de los dos años, en la segunda infancia o, más raramente, luego de la tercera década de la vida).

\section{Epidemiología}

La prevalencia estimada de EC en el mundo es uno cada 200 habitantes. En Argentina, datos de un estudio nacional multicéntrico y del Hospital "Alejandro Posadas" documentaron una incidencia entre uno en 840 y uno en 1000 nacidos vivos. La incidencia global en Europa es similar a la de nuestro medio, con diferencias regionales que van de uno cada 250 nacidos vivos (Suecia) a uno cada 4000 (Dinamarca).

Durante las últimas décadas se observó un claro incremento de su incidencia; se cree que este fenómeno se debe a la gran difusión de la enfermedad en los medios de comunicación, a la sospecha precoz en poblaciones de riesgo (quienes presentan antecedentes familiares o enfermedades autoinmunes) y a los nuevos métodos de diagnóstico serológico. 
La susceptibilidad a padecer esta entidad estaría determinada en gran parte por factores genéticos, como lo sugieren el aumento del riesgo de padecerla los familiares de primer y segundo grado de los individuos con diagnóstico de EC (10\% y $3 \%$, respectivamente) y la concordancia del $79 \%$ en los gemelos homocigóticos. Es frecuente que los familiares no presenten manifestaciones clínicas, pero sí suelen tener hallazgos histopatológicos en la biopsia duodenal. Existe asociación de esta enfermedad con otras afecciones, como se observa en el cuadro 4

Cuadro 4. Factores de riesgo asociados al desarrollo de enfermedad celíaca y magnitud de su impacto.

\begin{tabular}{l|c|c}
\multicolumn{1}{c|}{ Factor de riesgo } & Prevalencia (\%) & Riesgo Relativo \\
\hline Población general (EE.UU y Europa) & 0,7 a 1,0 & \\
\hline Familiares de primer grado de pacientes con EC & 4 a 5 & 6 \\
\hline Familiares de segundo grado & 3 & 3 \\
\hline Diabetes tipo 1 & 5 a 10 & 7 a 13 \\
\hline Sindrome de Down & 5 a 16 & 7 a 21 \\
\hline Deficiencia de IgA & 2 a 8 & 3 a 11 \\
\hline Sindrome de Williams & 8 & 11 \\
\hline Sindrome de Turner & 4 a 8 & 5 a 11 \\
\hline Enfermedad tiroidea autoinmune & 4,5 & 6 \\
\hline
\end{tabular}

\section{Fisiopatogenia}

Esta enfermedad multisistémica que produce una enteropatía autoinmune en individuos genéticamente susceptibles, está desencadenada por la proteína del gluten que se encuentra en el trigo, el centeno, la cebada y la avena (aunque la participación de este cereal ha sido puesto en duda, es muy difícil la producción de avena para consumo dietario sin contaminación con el gluten de trigo). La respuesta inmunitaria al gluten ocasiona una atrofia de las vellosidades, una hiperplasia de las criptas y un daño en la superficie del epitelio del intestino delgado, cuyo grado de afectación es mayor en su porción proximal y se extiende en sentido distal hasta una distancia variable. De manera característica, estos cambios patológicos revierten con la cesación de la ingesta de los cereales mencionados.

\section{Presentación clínica}

En la actualidad se reconocen cuatro formas de presentación de la EC: 1) sindromática o florida, 2) asintomática o silente, 3) latente y 4) potencial.

La presentación sindromática o florida incluye formas agudas $(78 \%)$, crónicas $(10 \%)$, asociadas a otras enfermedades como inmunodeficiencias, diabetes tipo 1, síndrome de Down, hipotiroidismo, síndrome de Sjögren o artritis reumatoidea juvenil $(11 \%)$ y mono u oligosintomáticas $(1 \%)$. En edades pediátricas, la presentación clásica de la mayoría de los pacientes se inicia con diarrea, enlentecimiento del crecimiento $(10 \%$ de los casos), distensión abdominal, vómitos o anorexia.

Los lactantes pueden presentarse irritables, difíciles de consolar e inapetentes. Pueden observarse palidez, prolapso rectal, susceptibilidad a las infecciones y la distensión abdominal, dedos en palillo de tambor, edemas, atrofia muscular, así como percentilos de talla y peso por debajo de 25. En las formas crónicas es característica la baja talla, en comparación con los hermanos y/o padres (es decir, menor que la esperada genéticamente) y suelen presentarse signos carenciales en la piel, las mucosas y las faneras. Son características la lengua depapilada (por desaparición de las papilas fungiformes), la queilitis angular y la alteración del esmalte dental.

Hoy en día es cada vez más prevalerte la enfermedad celíaca asintomática o silente (sin síntomas digestivos) pero con daño severo de la mucosa intestinal en personas diagnosticadas a través de la pesquisa de casos por el antecedente de EC en familiares directos.

En las formas atípicas los pacientes pueden presentar como única manifestación el retardo de crecimiento u otras anomalías endocrinológicas, como el hipopituitarismo secundario (probablemente causado por la desnutrición en las enfermedades prolongadas); hipomenorrea, amenorrea y abortos recurrentes en las mujeres; hipogonadismo, oligospermia, alteración de la morfología y de la motilidad de los espermatozoides, así como insensibilidad a los andrógenos en los varones. Otras manifestaciones extraintestinales descritas en la bibliografía incluyen neuropatía periférica, epilepsia intratable, calcificaciones occipitales, artritis y hepatitis crónica idiopática.

Una alta proporción de los pacientes con dermatitis herpetiforme posee alteraciones en la mucosa intestinal compatibles con EC. Como ya mencionamos, también es más frecuente el diagnóstico de esta entidad en pacientes que padecer otras afecciones autoinmunes (ej. enfermedades tiroideas, insuficiencia suprarrenal, anemia perniciosa, trombocitopenia autoinmune, sarcoidosis, diabetes mellitus y alopecia), en los afectados por el Síndrome de Down y en los que poseen otros trastornos inmunitarios como el déficit de IgA. Por otro lado, el riesgo de que los pacientes con enfermedad celíaca desarrollen otras enfermedades autoinmunes está directamente relacionado con su grado de exposición al gluten (adherencia al tratamiento).

La forma Latente incluye a pacientes celíacos con recuperación completa luego de dieta libre de gluten que permanecen silentes aún con dieta normal, y a pacientes con biopsia normal que desarrollarán enfermedad celíaca en forma tardía.

Por último, la forma Potencial afecta a pacientes que presentan marcadores serológicos positivos pero nunca biopsia compatible con EC.

\section{Laboratorio}

Los hallazgos de laboratorio en la EC son la anemia con déficit de hierro y de folatos, la hipoproteinemia (hipo albuminemia); los bajos niveles séricos de carotenos y la esteatorrea, la que puede llegar a $10 \mathrm{~g}$ de grasa por día.

\section{Sistemática de estudio}

Los marcadores serológicos son de gran ayuda en el diagnóstico de la EC, si bien aún existe cierta variabilidad en las características operativas reportadas por diferentes estudios (ver cuadro 5). Su mayor utilidad consiste en el tamizaje de los grupos de riesgo (familiares de primer grado de un paciente con enfermedad celíaca, en quienes padecen enfermedades asociadas y en casos de antecedente personal de hipersensibilidad a la proteína de la leche de vaca).

En los pacientes con baja sospecha de EC, el resultado negativo de los anticuerpos prácticamente descarta la enfermedad sin necesidad de realizar biopsia. Sin embargo en aquellos pacientes en los que exista alta sospecha, se deberá realizar serología y biopsia, ya que la negatividad de los marcadores serológicos no permite descartar esta entidad.

La biopsia de intestino sigue siendo el método indiscutible para realizar el diagnóstico de EC; debe hacerse sin restricción previa de gluten y luego de haber descartado causas frecuentes de malabsorción como las parasitosis (especialmente en Latinoamérica). La biopsia del intestino se realiza cuando existe sospecha clínica y/o positividad de las pruebas serológicas de tamizaje.

Los criterios para el diagnóstico de enfermedad celíaca son: 1) mucosa con daño típico en un paciente que recibe dieta con gluten; 2) remisión completa con la dieta sin gluten. Otro factor 
de importante peso diagnóstico en los últimos años, es el hallazgo de anticuerpos antigliadina y antitransglutaminasa que se negativizan con la dieta sin gluten.

El desafío con gluten (biopsiar nuevamente al paciente luego de incorporar el gluten a la dieta, esperando volver a encontrar los hallazgos histopatológicos de la enfermedad que habían remitido con el tratamiento) es discutido hoy en día, y muchos especialistas consideran que no sería necesario en todos los pacientes sino reservado para las situaciones de duda diagnóstica, sobre todo en las formas atípicas (ej. inicio antes de los dos años). En estos casos se realiza una biposia posdesafío si los síntomas aparecen inmediatamente o si hay empeoramiento de los marcadores serológicos con la reintroducción del alergeno.

En general, se recomienda repetir el dosaje de los anticuerpos luego de realizar una dieta libre de gluten durante un año. Si existe mejoría clínica y los anticuerpos se negativizan o disminuyen no sería necesario realizar otra biopsia.

Cuadro 5. Características operativas de los marcadores serológicos de la enfermedad celíaca.

\begin{tabular}{l|c|c}
\multicolumn{1}{c|}{ Anticuerpos } & Sensibilidad (\%) & Especificidad (\%) \\
\hline Antitransglutaminasa (IgA) & 90 a 100 & 95 a 100 \\
\hline Antiendomisio (IgA) & 93 a 100 & 98 a 100 \\
\hline Antigliadina (IgA) & 52 a 100 & 72 a 100 \\
\hline Antigliadina (IgG) & 83 a 100 & 47 a 94 \\
\hline
\end{tabular}

\section{Tratamiento}

Consiste en una dieta estricta libre de gluten de por vida. Aún la ingestión de pequeñas cantidades de esta proteína conlleva riesgos de recaída, además de un aumento del 20 al 120\% del riesgo de desarrollar linfoma intestinal. Por el contrario, se estima que si el paciente es adherente a su plan alimentario, este riesgo se asemejaría al de la población general (datos proporcionados por estudios con seguimiento a cinco años).

Cabe aclarar que existen múltiples alimentos manufacturados que contienen gluten en su preparación (ej. helados, yogur, dulce de leche, caramelos, fiambres, salchichas, salsas envasadas, té en saquitos, pasta de dientes, etc.). En Argentina existe una asociación sin fines de lucro llamada ACELA (Asistencia al Celíaco en Argentina) que se dedica a asesorar a los pacientes celíacos y a sus familias y que publica periódicamente listas de alimentos que pueden ser consumidos por estos pacientes.

\section{Enfermedad fibroquística}

Es una enfermedad hereditaria, autosómica recesiva (cromosoma 7) caracterizada por una disfunción generalizada de las glándulas exócrinas, que se manifiesta clínicamente por una neumopatía crónica, insuficiencia pancreática y eliminación elevada de electrolitos por el sudor.

Se observa en recién nacidos, lactantes y niños.

\section{Epidemiología}

Su frecuencia es de uno cada 3.200 nacidos vivos de origen caucásico y es el error congénito metabólico letal más frecuente en la raza blanca. Según el registro latinoamericano de fibrosis quísti$\mathrm{ca}$, se calcula que en este continente hay 16.000 pacientes afectados por esta enfermedad, de los cuales el $43,3 \%$ fue diagnosticado antes del primer año de vida.

Cuando se realiza un diagnóstico temprano (en el período neonatal), la sobrevida de estos pacientes en el mundo desarrollado puede llegar a los 30 años, aunque su pronóstico es más desfavorable en el cono sur y en los países subdesarrollados.

\section{Presentación clínica}

La más frecuente es la enfermedad pulmonar obstructiva crónica, que determina la mayor parte de la morbilidad y la expectativa de vida. Casi todos los pacientes desarrollan enfermedad pulmonar y sinusal crónica, mientras que el 85 al $90 \%$ tiene afección exócrina del páncreas. La fisiopatogenia de esta entidad se caracteriza por la obstrucción de los pequeños conductos de las glándulas exócrinas por secreciones ricas en glicoproteínas, a causa de una mutación en una proteína de membrana que actúa como transportador del cloro. Se producen secreciones espesas intraductales, que afectan la funcionalidad del pulmón, el páncreas, el hígado, el intestino, las glándulas salivales, los senos paranasales, la vesícula biliar y el aparato genitourinario (especialmente el epidídimo y los conductos deferentes).

Las manifestaciones intestinales pueden preceder en meses o en años a las pulmonares, en cuyo caso, el curso de la enfermedad es más benigno. El paciente se presenta desnutrido, pero con buen apetito. Suele acompañarse de esteatorrea y manifestaciones por pérdidas de vitaminas liposolubles (A, D, E y K), ya que en el 80 al $85 \%$ de los casos, los trastornos gastrointestinales constituyen manifestaciones de las lesiones pancreáticas que producen malabsorción. En el 10 al 20\% de los casos, el íleo meconial es la primera manifestación de esta entidad. Luego del período neonatal, el inicio del cuadro puede detectarse por obstrucciones o subobstrucciones intestinales o prolapso rectal ( $20 \%$ de los pacientes). Se ha observado que el $25 \%$ de los enfermos desarrolla cirrosis biliar, mientras que el $5 \%$ manifiesta algún tipo de enfermedad hepática.

Las banderas rojas que deben hacernos sospechar esta entidad en la infancia incluyen los antecedentes familiares y personales de polihidramnios, el íleo meconial, la ictericia persistente del recién nacido, la desnutrición, la deshidratación (por crisis de sudor), el prolapso rectal, las manifestaciones respiratorias recidivantes, las diarreas y el retraso del crecimiento.

\section{Sistemática de estudio}

El diagnóstico de esta enfermedad se basa en la anamnesis, el examen físico y el test del sudor. Este se considera positivo cuando se determina un valor mayor de $60 \mathrm{mEq}$ de cloro. La constatación de pérdida de grasa por la materia fecal, que suele superar los $10 \mathrm{~g} /$ día en los lactantes y los $30 \mathrm{~g} /$ día en los niños mas grandes (normal hasta $3,5 \mathrm{~g} /$ día) permite acercarnos al diagnóstico; así como la esteatorrea ácida que se obtiene luego del ultracentrifugado de la materia fecal (normal de 0 a $2 \%$ y patológico más de $4 \%$ ). Si la sospecha es alta, puede realizarse una prueba de Van de Kammer y quimiotripsina fecal. Por otro lado, las determinaciones en los recién nacidos del tripsinógeno inmunorreactivo en la sangre tienen una sensibilidad del $95 \%$ para detectar fibrosis quística.

En 1994 se sancionó en Argentina la Ley 23.413 que establece la obligatoriedad del rastreo universal de esta enfermedad en los neonatos junto con el hipotiroidismo congénito y la fenilcetonuria. Sin embargo todavía no existe consenso acerca de la repercusión poblacional y la costoefectividad de esta estrategia.

\section{Tratamiento}

Desde el punto de vista nutricional, se debe indicar una dieta apropiada con triglicéridos de cadena mediana que no requieren de la lipasa para su absorción y un aporte de las vitaminas liposolubles al doble o triple de las necesidades diarias, así como la terapia sustitutiva con enzimas pancreáticas asociada con antiácidos para evitar su degradación por el ácido clorhídrico gástrico.

Debe evitarse la constipación, humidificar las secreciones bronquiales y realizar drenaje de las secreciones para prevenir complicaciones. 
Sin embargo, a pesar de un tratamiento correcto la mayoría de estos niños nunca logra un crecimiento óptimo, el curso de la enfermedad los convierte en verdaderos pacientes crónicos y hace imprescindible su abordaje en el contexto de un equipo interdisciplinario.

\section{Sistemática de estudio de la diarrea crónica infantil}

\section{Interrogatorio}

Averiguar el tiempo de duración de la diarrea, su frecuencia, la consistencia de las deposiciones, su relación con la ingesta (diarrea osmótica) o con el ayuno (secretoria), si contiene moco, pus o sangre (en estos casos sugiere infección).

La edad del paciente puede brindar una orientación útil, ya que si el cuadro se inicia en los primeros meses de vida nos orientará hacia un déficit congénito de disacaridasas o a una intolerancia a la proteína de la leche de vaca; mientras que si su comienzo ocurre luego de los ocho meses el cuadro es sugestivo de enfermedad celíaca.

Indagar si el paciente tuvo fiebre u otros síntomas acompañantes, si hizo algún viaje reciente, si estuvo expuesto a animales, si hay alguien más en su casa que esté enfermo o si fue intervenido quirúrgicamente en alguna ocasión.

También es importante pesquisar algunos datos que permiten valorar la gravedad de la diarrea, como por ejemplo el cambio de frecuencia de la diuresis (que se modifica con el estado de hidratación del niño), el apetito, etc.

\section{Examen físico}

Deben valorarse el grado de hidratación a través de los signos vitales, la turgencia de la piel, las fontanelas y las mucosas, y los parámetros del crecimiento. Es importante determinar si existe afectación del estado nutricional desde el inicio del cuadro (ej. evaluación de las curva de crecimiento del peso y de la talla).

\section{Pruebas de laboratorio}

La primera etapa de la evaluación, que intentará determinar la etiología y la repercusión metabólica en el estado nutricional, incluye los siguientes pasos: 1) Objetivación de la diarrea crónica: cuantificación de la materia fecal diaria con y sin ayuno (normal hasta $15 \mathrm{~g} / \mathrm{kg} / \mathrm{día}$ ); 2) Estudio funcional de la materia fecal: evaluación de la presencia de sustancias no absorbidas a través de la determinación del pH fecal y de la pesquisa de cuerpos reductores; tinción de Sudán III (más de 10 gotas de grasa es positivo), esteatocrito o prueba cuantitativa de Van de Kammer (valores normales entre 1,1 y 2,5g/24h); 3) Estudios microscópicos en materia fecal: leucocitos, hematíes y eosinófilos, coprocultivo, parasitológico seriado y directo; 4) Toxina y cultivo para Clostridium difficile; 5) Determinación de sodio, potasio y osmolaridad en la materia fecal; 6) Pruebas en sangre: hemograma, ionograma, proteinograma electroforético, tiempo de protrombina, calcemia, fosfatemia y albuminemia; 7) Orina completa y urocultivo.

Si los estudios mencionados no sirvieron de orientación diagnóstica y si la historia clínica es compatible, puede continuarse con la segunda etapa, que consiste en la investigación de parásitos en el líquido duodenal obtenido por sondeo y el cultivo cuantitativo de bacterias en el líquido duodenal. En general, se requiere además una interconsulta con el especialista. Si hay sospecha de una etiología definida, en una tercera etapa se pueden solicitar en forma selectiva exámenes más dirigidos, como la prueba del sudor, la prueba del hidrógeno espirado, los anticuerpos antigliadina y antitransglutaminasa, el coprocultivo en medios especiales para gérmenes aeróbicos o anaeróbicos, la cuantificación de inmunoglobulinas séricas, y la biopsia de intestino delgado o recto.

Recibido el 10/01/2014 y aceptado el 20/01/2014

\section{Bibliografía recomendada}

Ammoury R. Malabsortive Disorders in Childhood. Pediatr Rev 2010; 31:407-416

Berkowitz C. Berkowitz's Pediatrics: A Primary Care Approach. American Academy of Pediatrics. 4th Edition, 2011.

Nelson. Textbook of Pediatrics. W.B. Saunders Company. 19th Edition, 2011.

García Martin M of Pediatrics. W.B. Saunders Company. 19th Edition, 2011.

Giersiepen K, Lelgemann M, Stuhldreher N, Ronfani L, Husby S, Koletzko S, et al. Accuracy of diagnostic antibody tests for coeliac disease in children: summary of an evidence report. J. Pediatr. Giersiepen K, Lelgemann M, Stuhldreh

Gastroenterol. Nutr. 2012;54(2):229-41.

Gomez J C, Sevaggio G S, y col. Prevalence of celiaca disease in Argentina: screening of an adult population in the La Plata

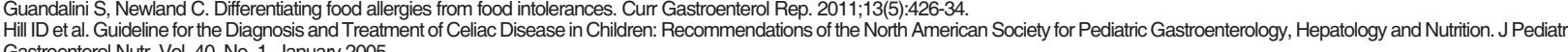

Gastroenterol Nutr, Vol. 40, No. 1, January 2005.
Husby S y col. European Society for Pediatric Gastroenterology, Hepatology, and Nutrition guidelines for the diagnosis of coeliac disease. J Pediatr Gastroenterol Nutr. 2012;54(1):136-60.

Husby S y col. European Society for Pediatric Gastroenterology, Hepatology, and Nutrition guidelines for the diagnosis
Ludvigsson JF y col. Timing of introduction of gluten and celiac disease risk. Ann. Nutr. Metab. 2012;60 Suppl 2:22-9.

Moore SR. Update on prolonged and persistent diarrhea in children. Curr. Opin. Gastroenterol. 2011;27(1):19-23.

Robinson KA y col. Management of infants with cystic fibrosis: a summary of the evidence for the cystic fibrosis foundation working group on care of infants with cystic fibrosis. J. Pediatr. 2009;155(6 Suppl):S94-S105.

Rua EC. Enfermedad Celíaca. PRONAP 2004. Módulo 1. 13-34

Saltzman RW y col. Gastrointestinal syndromes associated with food allergies. Curr Probl Pediatr Adolesc Health Care. 2012;42(7):164-90.

Salvatore S y col. Chronic enteropathy and feeding in children: an update. Nutrition. 2008;24(11-12):1205-16.

Toca MC. Diarrea aguda y crónica. PRONAP 2012. Módulo 2. 88-105

Working group reporto of the Second World Congress of pediatric gastroenterology, Hepatology and Nutrition 2004. Persistent and Chronic Diarrhea and Malabsorption. J pediatr gastroenterol Nutr 2004; 39:S711-S716 